\title{
INFLUÊNCIA DA RELAÇÃO VOLUMOSO: CONCENTRADO E DO TEMPO DE RETENÇÃO HIDRÁULICA SOB A BIODIGESTÃO ANAERÓBIA DE DEJETOS DE BOVINOS
}

\section{MARCO A. P. ORRICO JÚNIOR ${ }^{1}$, ANA C. A. ORRICO ${ }^{2}$, JORGE DE LUCAS JÚNIOR ${ }^{3}$}

RESUMO: O objetivo deste trabalho foi avaliar as possíveis alterações existentes na composição e no processo de biodigestão anaeróbia dos dejetos de bovinos em fase de terminação alimentados com diferentes proporções de volumoso: concentrado e com diferentes tempos de retenção hidráulica (TRH). Foram utilizados 24 biodigestores batelada de bancada com 12 litros de capacidade, dos quais 12 foram abastecidos com dejetos de bovinos alimentados com a dieta 1 (60\% volumoso:40\% concentrado) e dieta 2 (40\% volumoso:60\% concentrado) e submetidos a 30, 60, 90 e 120 dias de TRH. A eficiência do processo de biodigestão anaeróbia foi avaliada pelas reduções de sólidos totais, sólidos voláteis, fibra em detergente neutro, fibra em detergente ácido, celulose e número mais provável (NMP) de coliformes totais e termotolerantes, além dos potenciais de produção de biogás e metano. Os resultados mostraram que o aumento da proporção de volumoso na dieta levou a menor eficiência do processo, principalmente nos potenciais de produção de biogás e metano que foram em média $13 \%$ menor. Com relação ao NMP de coliformes totais e termotolerantes, foram observadas reduções significativas conforme aumentou TRH.

PALAVRAS CHAVE: dietas, biodigestor, energia, metano.

\section{EFFECTS OF ROUGHAGE: CONCENTRATE IN RELATION TO TIME OF HYDRAULIC RETENTION UNDER ANAEROBIC BIODIGESTION OF CATTLE MANURE}

\begin{abstract}
The aim of this survey was to evaluate the possible alterations that exist in composition and in anaerobic biodigestion process of cattle manure in phase of slaughter and fed with different proportions of roughage: concentrate and with different times of hydraulic retention (THR). 24 batch digesters of bench with capacity of 12 liters, from which 12 were provided with cattle manure that were fed with diet 1 (60\% roughage: $40 \%$ concentrate) and diet 2 (40\% roughage: $60 \%$ concentrate) and submitted to 30;60; 90 and 120 days of TRH were used. The efficiency of anaerobic biodigestion process was evaluated by reductions of total solids, volatile solids; neutral detergent fiber, acid detergent fiber, cellulose and the most probable number (MPN) of total and thermo tolerant coliforms, and production potential of biogas and methane were evaluated. Results showed that the increase of roughage proportion in diet conduced the smallest efficiency in the process, mainly in the production potential of biogas and methane, which were, in average, $13 \%$ smaller. Regarding to MPN of total and thermo tolerant coliforms, significative reductions as increased THR were observed.
\end{abstract}

KEYWORDS: diets, biodigestor, energy, methane.

\footnotetext{
${ }^{1}$ Doutorando em Zootecnia, Faculdade de Ciências Agrárias e Veterinárias, UNESP, Jaboticabal - SP, marcoorrico@ yahoo.com.br.

${ }^{2}$ Profa. Adjunta, Faculdade de Ciências Agrárias, UFGD, Dourados - MS, anaorrico@ufgd.edu.br.

${ }^{3}$ Prof. Titular, Faculdade de Ciências Agrárias e Veterinárias, UNESP, Jaboticabal - SP, jlucas@ fcav.unesp.br.

Recebido pelo Conselho Editorial em: 6-3-2009

Aprovado pelo Conselho Editorial em: 12-12-2009
} 


\section{INTRODUÇÃO}

Durante muitos anos a bovinocultura brasileira foi considerada uma atividade que trazia poucos prejuízos ambientais, principalmente pelo sistema de criação adotado, onde grandes áreas eram utilizadas para produção de um número reduzido de animais. Com isso havia uma deposição uniforme dos resíduos e em quantidades que o próprio meio tinha capacidade de absorver sem causar grandes problemas ao meio ambiente. Mas como a disponibilidade de área não acompanhou o crescimento da atividade, muitos produtores foram obrigados a mudar o sistema de criação, não só como forma de melhorar a produtividade, mas também de aumentar a velocidade de retorno econômico da atividade. Desta forma a terminação de animais em confinamento começou a ganhar força e nos últimos anos, a fazer com que o Brasil chegasse ao posto de segundo maior confinador do mundo com cerca de 2,7 milhões de animais em confinamento, ficando atrás apenas dos USA (ASSOCON, 2008).

Desta forma a criação intensiva de bovinos destinados ao abate tem contribuído, nos últimos anos, para o surgimento de sérios problemas ambientais devido à elevada deposição de resíduos e falta de pavimentação dos confinamentos, que dificulta a coleta e acentua os problemas de escoamento superficial e lixiviação RIBEIRO et al. (2007). Todos estes fatores aliados à falta de espaço físico para a disposição dos resíduos levam ao aumento das emissões de gases de efeito estufa, eutrofização de fontes de água e poluição do solo, principalmente pelo acúmulo de nitrogênio e fósforo (GÜNGÖR - DEMIRCI \& DEMIRER, 2004; ANGONESE et al., 2006; DEMIRER \& CHEN, 2005).

Para solução destes problemas é necessária a utilização de sistemas eficientes de tratamento destes resíduos, sem que estes onerem demasiadamente o sistema de produção, o que tornaria a atividade inviável. Dentre estes sistemas a biodigestão anaeróbia merece um destaque especial, pois além de promover o tratamento e reciclagem dos dejetos, promove agregação de valor às atividades com a produção do biogás e do biofertilizante, que podem ser revertidos ao sistema na economia de energia e fertilizantes (SILVA et al., 2005; ORRICO et al., 2007; SANTOS et al., 2007).

Segundo CÔTÉ et al. (2006) a biodigestão anaeróbia pode ser definida como uma complexa interação de microrganismos que degradam os diversos componentes orgânicos presentes no resíduo até a forma final de metano e dióxido de carbono, principalmente. Diferentes espécies de microrganismos atuam neste processo sendo, os não metanogênicos os responsáveis por hidrolisar polímeros orgânicos e fermentar-los para acetato, hidrogênio e dióxido de carbono e os metanogênicos, de converter esses subprodutos em metano. Os nutrientes contidos nos dejetos garantem a sobrevivência e reprodução dos microrganismos presentes durante a biodigestão anaeróbia, permitindo que ocorra a degradação da fração orgânica não estável e, portanto poluente, até a forma estável, o biofertilizante, além de produzir o biogás (ALVAREZ \& LIDÉN, 2008).

Como todo processo biológico a biodigestão anaeróbia depende de diversos fatores, os quais irão atuar sobre a degradação do material e consequente produção de biogás. Entre estes fatores, podem ser citados a temperatura, $\mathrm{pH}$, uso de inóculo, teores de sólidos totais e a composição do material (MASSÉ et al., 2008 e SOUZA et al., 2005). Dentre todos estes fatores a composição do material influencia diretamente o potencial de degradação do material, por isso a extensão da produção de biogás a partir dos dejetos é dependente da alimentação dos animais.

Os bovinos em geral se alimentam com grandes quantidades de alimento volumoso que será responsável pela geração de dejetos com maiores quantidades de componentes fibrosos (componentes da parede celular), o que irá acarretar em maior lentidão na produção de biogás, e provavelmente a eficiência do processo de biodigestão será menor. MOLLER et al. (2004) efetuaram a biodigestão anaeróbia dos dejetos de bovinos e observaram aumentos lineares na produção de biogás e dos potenciais de produção de biogás conforme se reduzia a quantidade de volumoso na dieta. Os autores encontraram um aumento de $50 \mathrm{~L} \mathrm{de} \mathrm{biogás} \mathrm{kg}^{-1}$ de sólidos voláteis, quando a proporção de volumoso da dieta caiu de 100 para $77 \%$. 
Diante da importância econômica e ambiental da reciclagem dos dejetos bovinos confinados, o objetivo deste trabalho foi avaliar a interferência da relação volumoso:concentrado sobre o processo de biodigestão anaeróbia dos dejetos de bovinos de corte em terminação, submetidos a diferentes tempos de retenção hidráulica (TRH).

\section{MATERIAL E MÉTODOS}

A pesquisa foi desenvolvida no Departamento de Engenharia Rural, com os dejetos coletados no setor de Bovinocultura de Corte, pertencentes à Faculdade de Ciências Agrárias e Veterinárias FCAV/UNESP, Jaboticabal.

Foram coletados dejetos de bovinos de corte, mantidos em confinamento e alimentados com duas dietas que variavam a relação volumoso:concentrado em $60 \%$ de volumoso e $40 \%$ de concentrado (Dieta 1) e $40 \%$ de volumoso e $60 \%$ de concentrado (Dieta 2), sendo que a fonte de volumoso foi o feno de Tifton 85 e o concentrado, formulado à base de milho, farelo de soja e mistura mineral. As dietas foram formuladas para atender as exigências de bovinos Canchim, com peso médio de $350 \mathrm{~kg}$ e idade em torno de 14 meses, provendo-se ganhos de peso de $1,2 \mathrm{~kg} \mathrm{dia}^{-1}$. Inicialmente os animais foram adaptados às dietas por 10 dias para então promover-se a coleta dos dejetos por 7 dias consecutivos. A coleta foi efetuada por raspagem dos dejetos contidos no piso das baias, que foi realizada uma vez ao dia. Para cada dieta foram utilizados quatro bovinos, alojados em baias individuais, sendo a alimentação oferecida em duas refeições diárias, compostas pelas proporções de concentrado e volumoso descritas. A composição dos dejetos provenientes de cada dieta está apresentada na Tabela 1.

TABELA 1. Caracterização dos dejetos produzidos por bovinos alimentados com dietas contendo $60 \%$ de volumoso (V) e $40 \%$ de concentrado (C) ou $40 \%$ de volumoso (V) e $60 \%$ de concentrado $(\mathrm{C})$. Characterization of manure that were produced by cattle fed with diets with $60 \%$ of roughage (V) and $40 \%$ of concentrated (C) or $40 \%$ of roughage $(V)$ and $60 \%$ of concentrated $(C)$.

\begin{tabular}{lcc}
\hline Componentes & $60 \mathrm{~V}: 40 \mathrm{C}$ & $40 \mathrm{~V}: 60 \mathrm{C}$ \\
\hline ST $(\%)$ & 18,25 & 18,60 \\
SV $(\%)$ & 15,78 & 16,32 \\
N $(\%)$ & 2,04 & 2,08 \\
FDN $(\%)$ & 56,32 & 53,66 \\
FDA (\%) & 34,44 & 31,64 \\
Celulose (\%) & 23,06 & 21,98 \\
Lignina (\%) & 8,34 & 6,64 \\
\hline
\end{tabular}

Os dejetos coletados foram utilizados para o abastecimento de biodigestores batelada de bancada com capacidade de 12 litros. Foram utilizados 24 biodigestores batelada de bancada (2 dietas x 4 TRH x 3 repetições (biodigestores). A quantidade de inóculo foi fixa e representou 15\% da massa seca utilizada no abastecimento dos biodigestores, sendo que, o inóculo foi obtido a partir do efluente de biodigestores contínuos estabilizados (produção de biogás e teor de metano constante) e alimentados com dejetos de bovinos de mesma idade que os utilizados no trabalho. Este procedimento permitiu que os microrganismos presentes no inóculo se adaptassem mais facilmente ao substrato, acelerando assim as produções de biogás.

Os biodigestores utilizados são constituídos, basicamente, por três cilindros retos de PVC com diâmetros de 20, 25 e $30 \mathrm{~cm}$, acoplados sobre uma placa de PVC com 2,5 cm de espessura e podem ser caracterizados como biodigestores de bancada, com capacidade média de 12 litros de substrato em fermentação, cada. Os cilindros de 20 e $30 \mathrm{~cm}$ encontram-se inseridos um no interior do outro, de tal forma que o espaço existente entre a parede externa do cilindro interior e a parede interna do cilindro exterior comporta um volume de água ("selo de água"), atingindo profundidade de $50 \mathrm{~cm}$. 
O cilindro de diâmetro intermediário tem uma das extremidades vedadas, conservando-se apenas uma abertura para descarga do biogás, e está emborcado no selo de água, para propiciar condições anaeróbias e armazenar o gás produzido.

Os volumes de biogás produzidos diariamente foram determinados medindo-se o deslocamento vertical dos gasômetros e multiplicando-se pela área da seção transversal interna dos gasômetros, ou seja, $0,0507 \mathrm{~m}^{2}$. Após cada leitura, os gasômetros foram zerados utilizando-se do registro de descarga do biogás. A correção do volume de biogás para as condições de 1 atm e $20{ }^{\circ} \mathrm{C}$ foi efetuada com base no trabalho de CAETANO (1985). O potencial de produção de biogás foi calculado utilizando-se dos dados de produção diária, e as quantidades de dejetos in natura, de substrato, de sólidos totais e de sólidos voláteis adicionados nos biodigestores durante o processo de biodigestão anaeróbia.

As análises da composição do biogás produzido em biodigestores abastecidos com dejetos de suínos foram realizadas semanalmente para determinação dos teores de metano $\left(\mathrm{CH}_{4}\right)$ e dióxido de carbono $\left(\mathrm{CO}_{2}\right)$, principalmente em cromatógrafo de fase gasosa Finigan GC-2001, equipado com as colunas Porapack Q e Peneira Molecular, e detector de condutividade térmica.

Os teores de ST, SV, DQO, DBO e NMP de coliformes totais e termotolerantes avaliados nos afluente e efluente dos biodigestores batelada de bancada foram determinados segundo metodologia descrita por APHA et al. (2005).

As amostras dos afluentes e efluentes coletadas durante o desenvolvimento da biodigestão anaeróbia foram pré-secadas a $60^{\circ} \mathrm{C}$, em estufa de circulação forçada de ar, por 48 horas. A seguir foram finamente moídas, em moinho de facas e então utilizadas para a determinação de fibras em detergente neutro e ácido, celulose e lignina segundo metodologias propostas por SILVA \& QUEIROZ (2006).

$\mathrm{Na}$ avaliação dos resultados referentes ao ensaio de biodigestão anaeróbia com dejetos provenientes de bovinos, alimentados por duas dietas adotou-se delineamento inteiramente casualizado, em esquema fatorial, constando de 8 tratamentos (2 dietas x 4 TRH e 3 repetições), com comparação de médias pelo teste de Tukey ao nível de $1 \%$ de probabilidade. Os resultados das variáveis obtidas foram submetidos à análise de variância utilizando o procedimento GLM (SAS, 2001).

\section{RESULTADOS E DISCUSSÃO}

Foram observadas (Tabela 2) diferenças significativas $(\mathrm{P}<0,01)$ nos parâmetros avaliados conforme houve aumento do tempo de retenção hidráulica, desta forma as maiores reduções foram observadas nos reatores operados com 120 dias de retenção hidráulica, independente da dieta utilizada. Avaliando o efeito do TRH sobre a biodigestão anaeróbia dos dejetos de bovinos leiteiros, AMARAL et al. (2004) encontraram para biodigestores operados com 30 dias de retenção hidráulica, reduções de SV que variaram de 29 a 33\%. Estes resultados são muito próximos aos encontrados neste trabalho, onde as reduções de SV foram de 28,35 e 32,40\% para as dietas de 60 e $40 \%$ de volumoso, respectivamente.

$\mathrm{Na}$ Tabela 2, pode ser observado o efeito da dieta sobre a eficiência do processo, onde o aumento da proporção concentrado na dieta dos animais favoreceu a degradação dos substratos. As reduções de ST, SV, FDN, FDA e celulose dos dejetos de bovinos que consumiram a dieta em $60 \%$ de concentrado, foram superiores $(\mathrm{P}<0,01)$ às obtidas a partir dos dejetos de bovinos alimentados com $40 \%$ de concentrado. 
TABELA 2. Redução (\%) de sólidos totais (ST), sólidos voláteis (SV), fibra em detergente neutro (FDN), fibra em detergente ácido (FDA) e celulose em substratos preparados a partir dos dejetos de bovinos de corte alimentados com dietas com diferente relação volumoso:concentrado, em diferentes tempos de retenção hidráulica (TRH). Reduction (\%) of total solids (ST), volatile solids (SV), neutral detergent fiber (FDN), acid detergent fiber (FDA) and cellulose in substrata that were prepared from cattle manure fed with diets with different proportions of roughage: concentrated, in different times of hydraulic retention (THR).

\begin{tabular}{|c|c|c|c|c|c|}
\hline Entrada & TRH 30 & TRH 60 & TRH 90 & TRH 120 & C.V.\% \\
\hline \multicolumn{6}{|c|}{ Redução ST (\%) } \\
\hline $60 \mathrm{~V}: 40 \mathrm{C}$ & $18,95 \mathrm{Bd}$ & $31,98 \mathrm{Bc}$ & $39,29 \mathrm{Bb}$ & $45,77 \mathrm{Ba}$ & \multirow{2}{*}{3,55} \\
\hline \multirow[t]{2}{*}{ 40V:60C } & $34,44 \mathrm{Ad}$ & $42,28 \mathrm{Ac}$ & $52,66 \mathrm{Ab}$ & $61,25 \mathrm{Aa}$ & \\
\hline & \multicolumn{5}{|c|}{ Redução SV (\%) } \\
\hline $60 \mathrm{~V}: 40 \mathrm{C}$ & $28,35 \mathrm{Bd}$ & $38,28 \mathrm{Bc}$ & $52,63 \mathrm{Bb}$ & $61,47 \mathrm{Ba}$ & \multirow{2}{*}{5,72} \\
\hline \multirow[t]{2}{*}{ 40V:60C } & $32,40 \mathrm{Ad}$ & $40,94 \mathrm{Ac}$ & $55,77 \mathrm{Ab}$ & $63,42 \mathrm{Aa}$ & \\
\hline & \multicolumn{5}{|c|}{ Redução FDN (\%) } \\
\hline $60 \mathrm{~V}: 40 \mathrm{C}$ & $32,92 \mathrm{Ac}$ & $55,78 \mathrm{Ab}$ & $61,25 \mathrm{Ab}$ & $75,60 \mathrm{Aa}$ & \multirow{2}{*}{8,66} \\
\hline \multirow[t]{2}{*}{ 40V:60C } & $36,80 \mathrm{Ad}$ & $49,95 \mathrm{Ac}$ & $61,17 \mathrm{Ab}$ & $89,40 \mathrm{Aa}$ & \\
\hline & \multicolumn{5}{|c|}{ Redução FDA (\%) } \\
\hline 60V:40C & $19,72 \mathrm{Bc}$ & $35,79 \mathrm{Bb}$ & $43,00 \mathrm{Bab}$ & $47,73 \mathrm{Ba}$ & \multirow{2}{*}{9,56} \\
\hline \multirow[t]{2}{*}{ 40V:60C } & $30,56 \mathrm{Ac}$ & $41,38 \mathrm{Ab}$ & $50,26 \mathrm{Aab}$ & $57,77 \mathrm{Aa}$ & \\
\hline & \multicolumn{5}{|c|}{ Redução Celulose (\%) } \\
\hline $60 \mathrm{~V}: 40 \mathrm{C}$ & $25,45 \mathrm{Bd}$ & $40,03 \mathrm{Bc}$ & $49,65 \mathrm{Bb}$ & $59,77 \mathrm{Ba}$ & \multirow[b]{2}{*}{9,97} \\
\hline $40 \mathrm{~V}: 60 \mathrm{C}$ & $47,30 \mathrm{Ad}$ & $52,77 \mathrm{Ac}$ & $71,49 \mathrm{Ab}$ & $84,60 \mathrm{Aa}$ & \\
\hline
\end{tabular}

Na coluna, letras maiúsculas comparam dietas e, na linha, letras minúsculas comparam tempos de retenção. Médias seguidas de letras distintas diferem entre si, pelo teste de Tukey $(\mathrm{P}<0,01)$. C.V. - coeficiente de variação.

O benefício ocasionado pela adição de alimento concentrado à dieta dos animais sobre a degradação dos substratos pode estar relacionado com os menores teores de constituintes fibrosos (FDN, FDA conforme dados apresentados na Tabela 1), que em menores quantidades podem ter favorecido as maiores reduções de ST e SV. Resultado semelhante foi encontrado por AMORIM (2004) ao estudar a interferência da relação volumoso e concentrado, no processo de biodigestão anaeróbia dos dejetos de cabritas Saanen. A autora encontrou alta correlação entre o aumento da quantidade de concentrado na dieta e a eficiência de degradação do material. As médias de redução de SV foram: $45 \%$ para a dieta contendo $40 \%$ de volumoso e $60 \%$ de concentrado, $35 \%$ para a dieta contendo $60 \%$ de volumoso e $40 \%$ de concentrado e $27 \%$ para a dieta contendo $80 \%$ de volumoso e $20 \%$ de concentrado.

A maior degradação dos dejetos provenientes da dieta com maior proporção de concentrado refletiu diretamente sobre a produção e os potenciais de produção de biogás e metano, de modo que com o aumento da qualidade dos dejetos (maior proporção de concentrado na dieta), maiores foram as produções (Tabelas 3 e 4). 
TABELA 3. Produções totais $\left(\mathrm{m}^{3}\right)$ de biogás e metano e porcentagens relativa (120 dias de retenção) e de metano, aos 30; 60; 90 e 120 dias de retenção, em substratos preparados a partir dos dejetos de bovinos de corte alimentados com dietas com diferente relação volumoso:concentrado, em diferentes tempos de retenção hidráulica $(\mathrm{TRH})$. Total productions $(\mathrm{m} 3)$ of biogas and methane and relative percentages (120 days of retention) and of methane on $30,60,90$ and 120 days of retention, in prepared substrata from cattle manure fed with diets with different proportions of roughage: concentrate, in different times of hydraulic retention (THR).

\begin{tabular}{lcccc}
\hline \multirow{2}{*}{ TRH } & \multicolumn{2}{c}{ L de biogás } & \multicolumn{2}{c}{${\mathrm{L} \mathrm{de} \mathrm{CH}_{4}}$} \\
\cline { 2 - 5 } & $60 \mathrm{~V}: 40 \mathrm{C}$ & $40 \mathrm{~V}: 60 \mathrm{C}$ & $60 \mathrm{~V}: 40 \mathrm{C}$ & $40 \mathrm{~V}: 60 \mathrm{C}$ \\
\hline 30 & $110 \mathrm{Ba}$ & $140 \mathrm{Aa}$ & $80 \mathrm{Ba}$ & $90 \mathrm{Aa}$ \\
60 & $190 \mathrm{Bb}$ & $220 \mathrm{Ab}$ & $140 \mathrm{Bb}$ & $150 \mathrm{Ab}$ \\
90 & $210 \mathrm{Bc}$ & $240 \mathrm{Ac}$ & $160 \mathrm{Bc}$ & $170 \mathrm{Ac}$ \\
120 & $220 \mathrm{Bc}$ & $250 \mathrm{Ac}$ & $170 \mathrm{Bd}$ & $210 \mathrm{Ad}$ \\
\hline C.V.\% & & 2,66 & & 4,21 \\
\hline
\end{tabular}

$\mathrm{Na}$ linha, letras maiúsculas comparam dietas e, na coluna letras minúsculas comparam tempos de retenção. Médias seguidas de letras distintas diferem entre si, pelo teste de Tukey $(\mathrm{P}<0,01)$. C.V.\% - coeficiente de variação

TABELA 4. Potenciais médios de produção de biogás em substratos preparados a partir dos dejetos de bovinos de corte alimentados com dietas com diferente relação volumoso: concentrado, em diferentes tempos de retenção hidráulica (TRH). Average potential of biogas production in prepared substrata from cattle manure fed with diets with different proportions of roughage: concentrate, in different times of hydraulic retention (THR).

\begin{tabular}{|c|c|c|c|c|c|}
\hline \multirow{2}{*}{ Dietas } & TRH 30 & TRH 60 & TRH 90 & TRH 120 & C.V.\% \\
\hline & \multicolumn{5}{|c|}{$\mathrm{L}_{\text {biogás } \mathrm{kg}^{-1} \mathrm{ST} \text { adicionado }}$} \\
\hline $60 \mathrm{~V}: 40 \mathrm{C}$ & $160 \mathrm{Bc}$ & $300 \mathrm{Bb}$ & $340 \mathrm{Bab}$ & $370 \mathrm{Ba}$ & \multirow{2}{*}{7,80} \\
\hline \multirow[t]{2}{*}{$40 \mathrm{~V}: 60 \mathrm{C}$} & $200 \mathrm{Ac}$ & $320 \mathrm{Ab}$ & $370 \mathrm{Aab}$ & 420Aa & \\
\hline & \multicolumn{5}{|c|}{$\mathrm{L} \mathrm{CH}_{4} \mathrm{~kg}^{-1} \mathrm{ST}$ adicionado } \\
\hline $60 \mathrm{~V}: 40 \mathrm{C}$ & $110 \mathrm{Bd}$ & $220 \mathrm{Bc}$ & $260 \mathrm{Bb}$ & $300 \mathrm{Ba}$ & \multirow{2}{*}{8,37} \\
\hline \multirow[t]{2}{*}{ 40V:60C } & 130Ad & $230 \mathrm{Ac}$ & $270 \mathrm{Ab}$ & 350Aa & \\
\hline & \multicolumn{5}{|c|}{ L biogás $\mathrm{kg}^{-1} \mathrm{SV}$ adicionado } \\
\hline $60 \mathrm{~V}: 40 \mathrm{C}$ & $180 \mathrm{Bc}$ & $350 \mathrm{Bb}$ & $400 \mathrm{Bab}$ & $430 \mathrm{Ba}$ & \multirow{2}{*}{12,28} \\
\hline \multirow[t]{2}{*}{ 40V:60C } & $230 \mathrm{Ac}$ & $380 \mathrm{Ab}$ & 440Aab & 500Aa & \\
\hline & \multicolumn{5}{|c|}{$\mathrm{L} \mathrm{CH}_{4} \mathrm{~kg}^{-1} \mathrm{SV}$ adicionado } \\
\hline $60 \mathrm{~V}: 40 \mathrm{C}$ & $130 \mathrm{Bc}$ & $200 \mathrm{Bb}$ & $300 \mathrm{Bab}$ & $350 \mathrm{Ba}$ & \multirow{2}{*}{11,92} \\
\hline $40 \mathrm{~V}: 60 \mathrm{C}$ & $150 \mathrm{Ac}$ & $260 \mathrm{Ab}$ & 320Aab & 410Aa & \\
\hline
\end{tabular}

Na coluna, letras maiúsculas comparam dietas e, na linha, letras minúsculas comparam tempos de retenção. Médias seguidas de letras distintas diferem entre si pelo teste de Tukey $(\mathrm{P}<0,01)$. C.V. - coeficiente de variação.

Não foram observadas diferenças significativas ( $\mathrm{P}>0,01)$ entre o TRH de 90 e 120 dias para a produção e aos potenciais de produção de biogás, entretanto houve diferença $(\mathrm{P}<0,01)$ em relação à produção e os potenciais de produção de metano. Isto se deve ao aumento no teor de metano no biogás à medida que aumentou o TRH. ALVAREZ et al. (2006) estudaram o efeito da temperatura, pressão atmosférica e TRH sobre a biodigestão anaeróbia dos dejetos de bovinos e observaram que o teor de metano aumentou de 46 para $61 \%$ quando o TRH foi alterado de 20 para 50 dias.

Com relação às dietas testadas, foi observado um aumento de $23 \%$ no volume de metano produzido na dieta com $60 \%$ concentrado com relação à dieta de $40 \%$ de concentrado, tendo como base para o cálculo as produções de metano no maior TRH testado (120 dias). Quando se faz a mesma comparação com base nos potenciais de produção de metano por kg de SV adicionado, o aumento encontrado foi de $17 \%$. Os potenciais de produção de metano encontrado neste trabalho 
são superiores aos encontrados por ALVAREZ et al. (2006), que observaram um potencial de produção de metano de $131 \mathrm{~L} \mathrm{~kg}^{-1} \mathrm{SV}$ adicionado, quando se submeteu dejeto de bovino a um TRH de 50 dias, o motivo desta diferença pode estar na dieta oferecida aos animais, na qual era baseada apenas em alimento volumoso. MOLLER et al. (2004) estudaram potenciais de produção de metano de bovinos submetidos a diferentes dietas e encontraram potencial de $100 \mathrm{~L} \mathrm{~kg}^{-1} \mathrm{SV}$ adicionado para uma dieta $100 \%$ de volumoso ou seja muito próximo ao encontrado por ALVAREZ et al. (2006).

Ainda com relação ao estudo de MOLLER et al. (2004) também foi observado aumento nos potenciais de produção de metano conforme se aumentou a proporção de concentrado na dieta dos bovinos. Os autores encontraram potenciais de produção de metano de 150 a $207 \mathrm{~L} \mathrm{~kg}^{-1}$ de SV adicionado, para as dietas de 23 e $48 \%$ de concentrado, respectivamente.

Na Tabela 5, são apresentados os valores de NMP de coliformes totais e termotolerantes encontrados nos afluentes e nos efluentes de cada TRH testado. Foram observadas diferenças $(\mathrm{P}<0,01)$ entre os diferentes TRHs, de forma que quanto maior foi o tempo de permanência do material no interior dos biodigestores maiores foram as reduções de coliformes totais $\mathrm{e}$ termotolerantes. Entretanto não foram encontradas diferenças $(\mathrm{P}>0,01)$ entre as dietas no que diz respeito à população de coliformes totais e termotolerantes nos substratos durante a biodigestão anaeróbia. As reduções de coliformes totais e fecais foram elevadas, acima de 99,98\%, demonstrando a eficiência do processo de biodigestão anaeróbia na remoção de microrganismos indicadores de poluição fecal.

TABELA 5. Números mais prováveis (NMP/100 mL) de coliformes totais e termotolerantes em substratos preparados a partir dos dejetos de bovinos de corte alimentados com dietas com diferente relação volumoso:concentrado, em diferentes tempos de retenção hidráulica (TRH). The most probable number (NMP/100ml) of total and thermo tolerant coliforms in prepared substrata from cattle manure fed with diets with different proportions of roughage: concentrate, in different times of hydraulic retention (THR).

\begin{tabular}{lrrrrr}
\hline \multirow{2}{*}{ Dietas } & Afluente & TRH 30 & TRH 60 & TRH 90 & TRH 120 \\
\cline { 2 - 6 } & \multicolumn{5}{c}{ Coliformes Totais } \\
\hline 60V:40C & 46000000 & $93000 \mathrm{Aa}$ & $930 \mathrm{Ab}$ & $91 \mathrm{Ac}$ & 0Ac \\
40V:60C & 1100000000 & $210000 \mathrm{Aa}$ & $975 \mathrm{Ab}$ & $230 \mathrm{Ac}$ & $23 \mathrm{Ac}$ \\
\hline \multicolumn{5}{c}{ Coliformes Termotolerantes } \\
\hline $60 \mathrm{~V}: 40 \mathrm{C}$ & 38700000 & $87400 \mathrm{Aa}$ & $930 \mathrm{Ab}$ & $91 \mathrm{Ac}$ & $0 \mathrm{Ac}$ \\
40V:60C & 998000000 & $210000 \mathrm{Aa}$ & $975 \mathrm{Ab}$ & $230 \mathrm{Ac}$ & $23 \mathrm{Ac}$ \\
\hline
\end{tabular}

Na coluna, letras maiúsculas comparam dietas e, na linha, letras minúsculas comparam tempos de retenção. Médias seguidas de letras distintas diferem entre si, pelo teste de Tukey $(\mathrm{P}<0,01)$.

Resultados semelhantes foram encontrados por COTÉ et al. (2006) que observaram eficiência de 97,94 a 100\% nas reduções de coliformes termotolerantes e totais durante a biodigestão anaeróbia dos dejetos de suínos, mesmo quando estes foram submetidos a condições de baixa temperatura $\left(20^{\circ} \mathrm{C}\right)$. Segundo os mesmos autores a eficiência na redução dos microrganismos patogênicos está associada à temperatura de fermentação e ao TRH utilizado, sendo que quanto maiores forem os seus valores, mais eficientes será a redução de patógenos.

Em estudo realizado por MENTZ et al. (2004), a biodigestão anaeróbia foi eficiente para eliminar o parasita Fasciola hepatica presente no dejeto de bovino. Segundo os autores para que possa ser utilizado com fertilizante sem acarretar problemas à saúde animal e humana, o período de retenção do material não deve ser inferior a 42 dias.

Os números de coliformes nos efluentes, a partir do TRH de 60 dias, não ultrapassaram os limites recomendados para os rios de classe 2 , destinados à aquicultura ou à recreação de contato 
primário, (CONAMA, 2005), que foram preconizados em no máximo 1.000 coliformes termotolerantes por $100 \mathrm{~mL}$ de efluente. Estes efluentes, segundo disposição do CONAMA (2005), poderão ser empregados na irrigação de hortaliças, plantas frutíferas e de parques, jardins, campos de esporte e lazer, com os quais o público possa vir a ter contato direto. Esses resultados demonstram a segurança do uso dos biofertilizantes em áreas agrícolas de forma a agregar valor à produção sem prejuízos ao meio ambiente e à saúde da população.

\section{CONCLUSÕES}

Dietas com maiores proporções de volumoso promovem um pior desempenho do processo de biodigestão anaeróbia dos dejetos. Com isso a dieta com maior proporção de concentrado promoveu aumento de até $23 \%$ na produção de metano necessitando inclusive, de menores tempos de retenção (quatro dias a menos), em comparação com os substratos originados de animais que consumiram maiores proporções de volumoso.

\section{REFERÊNCIAS}

ALVAREZ, R.; LIDÉN, G. Semi-continuous co-digestion of solid slaughterhouse waste, manure, and fruit and vegetable waste. Renewable Energy, Brighton, v.33, n.2, p.726-734, 2008.

ALVAREZ, R.; VILLCA, S.; LIDÉN, G. Biogas production from llama and cow manure at high altitude. Biomass and Bioenergy, Aberdeen, v.30, n.3, p.66-75, 2006.

AMARAL, C.M.C.; AMARAL, L.A.; LUCAS JÚNIOR, J.; NASCIMENTO, A.A.; FERREIRA, D.S.; MACHADO, M.R.F. Biodigestão anaeróbia de dejetos de bovinos leiteiros submetidos a diferentes tempos de retenção hidráulica. Ciência Rural, Santa Maria, v.34, n.6, p.1.897-1.902, 2004.

AMERICAN WATER WORKS. Standard methods for examination of water and wastewater. $21^{\text {th }}$ ed. Washington: American Water Works Association, 2005. 1.368 p.

AMORIM, A.C.; LUCAS JÚNIOR, J.; RESENDE, K.T. Biodigestão anaeróbia de dejetos de caprinos obtidos nas diferentes estações do ano. Engenharia Agrícola, Jaboticabal, v.24, n.1, p.1624, 2004.

ANGONESE, A.R.; CAMPOS, A.T.; CUNHA, F.; MATSUO, M.S.; ZACARIM, C.E. Eficiência energética de sistema de produção de suínos com tratamento dos resíduos em biodigestor. Revista Brasileira de Engenharia Agrícola Ambiental, Campina Grande, v.10, n.3, p.745-750, 2006.

ASSOCON. ASSOCIAÇÃO NACIONAL DOS CONFINADORES. Disponível em: $<\mathrm{http}: / /$ www.assocon.com.br/not\%2046\%202.htm>. Acesso em: $11 \mathrm{dez} .2008$.

CAETANO, L. Proposição de um sistema modificado para quantificação de biogás. $1985.75 \mathrm{f}$.

Dissertação (Mestrado em Energia na Agricultura) - Faculdade de Ciências Agronômicas, Universidade Estadual Paulista, Botucatu, 1985.

CONAMA. CONSELHO NACIONAL DO MEIO AMBIENTE. Padrões de qualidade para os parâmetros monitorados na rede de monitormento. Resolução CONAMA 20/86. Disponível em: $<$ http://www.cetesb.sp.gov.br/QualidadeRios/anexo2>. Acesso em: 1ํo abr. 2005.

CÔTE, C.; MASSE, D.I.; QUESSY, S. Reduction of indicator and pathogenic microorganisms by psychrophilic anaerobic digestion in swine slurries. Bioresource Technology, Oxford, v.97, n.1, p.686-691, 2006.

DEMIRER, G.N.; CHEN, S. Two-phase anaerobic digestion of unscreened dairy manure. Process Biochemistry, Shanghai, v.40, n.4, p.3.542-3.549, 2005.

GÜNGÖR-DEMIRCI, G.; DEMIRER, G.N. Effect of initial COD concentration, nutrient addition, temperature and microbial acclimation on anaerobic treatability of broiler and cattle manure.

Bioresource Technology, Oxford, v.93, n.2, p.109-117, 2004. 
MASSÉ, D.I.; MASSE, L.; HINCE, J.F.; POMAR, C. Psychrophilic anaerobic digestion biotechnology for swine mortality disposal. Bioresource Technology, Oxford, v.99, n.3, p.7.3077.311, 2008.

MENTZ, M.B.; WIEST, J.M.; GONCALVES, P.C. Viabilidade de ovos de Fasciola hepatica de bovinos em sistema de biodigestão anaeróbia. Arquivo Brasileiro de Medicina Veterinária e Zootecnia, Belo Horizonte, v.56, n.4, p.550-553, 2004.

MOLLER, H.B.; SOMMER, S.G.; AHRING, B.K. Methane productivity of manure, straw and solid fractions of manure. Biomass Bioenergy, Oxford, v.26, n.3, p.485-495, 2004.

ORRICO, A.C.A.; LUCAS JÚNIOR, J.; ORRICO JÚNIOR, M.A.P. Caracterização e biodigestão anaeróbia dos dejetos de caprinos. Engenharia Agrícola, Jaboticabal, v.27, n.3, p.639-647, 2007.

RIBEIRO, G.M.; SAMPAIO, A.A.M.; FERNANDES, A.R.M.; HENRIQUE, W.; SUGOHARA, A.; AMORIM, A.C. Efeito da fonte proteica e do processamento físico do concentrado sobre a terminação de bovinos jovens confinados e o impacto ambiental dos dejetos. Revista Brasileira de Zootecnia, Viçosa - MG, v.36, n.6, p.2.082-2.091, 2007.

SAS. STATISTICAL ANALYSIS SYSTEM. SAS system for Windows. Versão: 8.2. Cary, 2001. CDROM.

SANTOS, T.M.B.; LUCAS JÚNIOR, J.; SILVA, F.M. Avaliação do desempenho de um aquecedor para aves adaptado para utilizar biogás como combustível. Engenharia Agrícola, Jaboticabal, v.27, n.3, p.658-664, 2007.

SILVA, F.M.; LUCAS JÚNIOR, J.; BENINCASA, M.; OLIVEIRA, E. Desempenho de um aquecedor de água a biogás. Engenharia Agrícola, Jaboticabal, v.25, n.3, p.608-614, 2005.

SILVA, D.J.; QUEIROZ, A.C. Análise de alimentos: métodos químicos e biológicos. 3.ed. Viçosa MG: Editora Universitária, 2006. 166 p.

SOUZA, C.F.; LUCAS JÚNIOR, J.; FERREIRA, W.P.M. Biodigestão anaeróbia de dejetos de suínos sob efeito de três temperaturas e dois níveis de agitação do substrato: considerações sobre a partida. Engenharia Agrícola, Jaboticabal, v.25, n.2, p.530-539, 2005. 